\title{
Specification of the system application for the different tariffs during the consumption time of electricity by industrial enterprises
}

\author{
Khakim Muratov ${ }^{1}$, Kamoliddin Kodirov ${ }^{1 *}$, and Alijon Kushev ${ }^{1}$ \\ ${ }^{1}$ Uzbekenergo "JSC Scientific and Technical Center" LLC, 100076 Tashkent, Uzbekistan
}

\begin{abstract}
This article is devoted to such issues as smoothing the schedule of loads of manufacturing factories in the "intensive" periods due to the correct use of the system of tariffs, which is stratified by time. It is possible to achieve smoothing of the load schedule of the energy system through the correct use of the time-stratified tariff system by taking into account the above-mentioned issue. Proper use of the time-stratified tariff system by consumers will reduce the load period of the energy system and change its modes.
\end{abstract}

\section{Introduction}

The system of direct tariffs regulates the relationship between electricity generating and supplying enterprises and electricity consumers [1,2].

The 1, 2, and 3-shift operation modes of many manufacturing enterprises, with the "intensive" time in the power system, lead to voltages in the operating mode of the power system of the enterprise power consumption peak. Their average night-time electricity consumption is $20-25 \%$ of the daytime shift. This, in turn, indicates that electricity consumption is low at night and rises sharply during the day.

One of the main challenges for enterprises is to adjust load schedules to ensure normal and cost-effective energy consumption [3].

The introduction of time-varying tariffs in the energy consumption regimes of manufacturing enterprises will reduce the increase in energy consumption in "intensive" periods. In the energy system, the load period is introduced into the energy system of timestratified tariffs to reduce consumption in "intensive" periods. A two-period day and night tariff system is used for two periods of the day.

In the energy system, a two-period system of time-stratified tariffs is used during the period of electricity consumption by manufacturing enterprises in Japan, Germany, England, Russia, Belarus, Ukraine, Kazakhstan, and many other developed countries. Manufacturing enterprises in these countries are voluntarily connected to two-period differentiated tariffs. The fact that most manufacturing enterprises consume electricity at night, the transition to a two-period stratified tariff system leads to a reduction in the amount of electricity costs of enterprises and brings significant economic benefits to the enterprise $[4,5]$.

* Corresponding author: kamoliddin.8484@mail.ru 
In the energy market, tariff policy is used to regulate technical and economic issues, as a result, it is possible to eliminate the monopoly of high prices, but prices must be such that they have to satisfy the electricity system $[6,7]$.

The formation of a form of tariffs to account for electricity in order to cover the costs of electricity generation will greatly help to solve the problem and stimulate consumers with energy savings, increase the supply of quality and reliable electricity. In addition, research shows that tariff policy will be one of the key factors in balancing [8].

The consumer is ready to change electricity tariffs at any time, only when it is an economic benefit for suppliers and consumers in this direction. Nevertheless, the transition to timestratified tariffs requires the resolution of serious legal issues. The definition and approval of norms of power consumption cycles in manufacturing enterprises should be socially based $[9,10]$.

\section{Methods}

Figures In manufacturing enterprises and other consumers of electricity, they can pay at reduced prices for electricity as a result of the application of time-varying tariffs during times of "intensive" electricity consumption.

The economic feasibility of reducing the maximum load on consumers during the maximum load periods of the power system is characterized by the following:

$$
\mathrm{C}_{0} \leq \mathrm{C}_{\text {max.dow. }} /\left(1+\Pi_{\mathrm{p}} / \mathrm{Z}_{\text {pr. }}\right)
$$

where $\Pi_{p}-$ the projected estimated profit of the enterprise, (UZS);

$\mathrm{Z}_{\mathrm{pr} .}-$ costs of manufacturing product, (UZS);

$\mathrm{C}_{\mathrm{o}}$ - payment for additional electricity detected by electricity meters, (UZS/kWh);

$\mathrm{C}_{\text {max.dow. }}$ - the maximum load of the enterprise during the period of maximum loads in the power system (The cost of payment for $1 \mathrm{~kW}$ ) $\mathrm{kW} / \mathrm{UZS}$ [11].

The overall economic effect through the measures taken to adjust the load schedule is expressed as follows:

$$
Э_{\mathrm{r}}=\left(\mathrm{P}_{\mathrm{aT}}-\mathrm{C}_{0}\right)\left(\mathrm{P}_{\mathrm{Max}}-\mathrm{P}_{\mathrm{Max}}^{1}\right) ;
$$

where $\mathrm{P}_{\text {мах }}$ - the maximum load of the enterprise at the time of maximum load of the power system, $(\mathrm{kW})$

$\mathrm{P}_{\text {Max }}^{\prime}$ - the last load after applying this measure, $(\mathrm{kWh})$.

The cost of adjusting the load schedule can be determined as follows:

$$
\mathrm{Z}=\mathrm{E}^{*} \Delta \kappa+\Delta \mathrm{U}
$$

where $\Delta \kappa$ - additional capital expenditures (to adjust the schedule);

$\mathrm{E}$ - the aggregate coefficient allocated to annual capital expenditures;

$\Delta \mathrm{U}$ - changes in the year to adjust the schedule.

The final specific cost of reducing the maximum load of the enterprise during the maximum loads of the power system is expressed as follows:

$$
\mathrm{C}_{0}=\mathrm{Z} / \mathrm{P}_{\text {Max }}-\mathrm{P}_{\text {Max }}^{\prime} \leq \mathrm{C}^{*}{ }_{\text {max.dow. }}
$$

where $\mathrm{P}_{\text {мах }}$ and $\mathrm{P}_{\text {мах }}^{\prime}$ - indicates the maximum load time of the power system, the maximum load of the enterprise, the capacity before and after the application of the measure. 
$\mathrm{C}_{0}$ - the cost of payment for the consumption of $1 \mathrm{kWh}$ for the maximum load of the enterprise at the maximum load of the power system (UZS / $\mathrm{kWh}$ );

$\mathrm{C}^{*}$ max.dow. - Payment value for $1 \mathrm{kWh}$ of maximum load during the maximum load period of the power system (UZS / $\mathrm{kWh}$ ).

If the measures taken to adjust the schedule of electricity consumption in enterprises (tariff system for electricity consumption) do not require additional capital expenditures, then the economic effect is determined by the difference between previous and subsequent total energy prices, i.e.:

$$
\Delta \mathrm{E}_{3}=\mathrm{C}_{1}-\mathrm{C}_{2}=\mathrm{Z}_{1} \mathrm{~A}_{1}-\mathrm{Z}_{2} \mathrm{~A}_{2}
$$

where $\Delta \mathrm{C}_{\ni}$ - the cost of one saved electricity, (kWh / UZS);

$\mathrm{C}_{1}, \mathrm{C}_{2}$ - the price of electricity before and after utilizing the method, (kWh / UZS);

$\mathrm{Z}_{1}, \mathrm{Z}_{2}-$ Electricity costs, (kWh / UZS);

$\mathrm{A}_{1}, \mathrm{~A}_{2}$ - Annual electricity consumption in the considered cases (kWh / UZS).

It is more beneficial to use technological measures in the development of organizational and technical measures to save electricity [12].

The minimum and maximum electricity consumption of "Wangda Metal" LLC in 2017 was higher during the day than during the normal tariff period. The main equipment of the enterprise was working during the day. During the night, the plant was shut down and all equipment was turned off. During the night, the plant had almost no electricity consumption. The company was paying for the electricity consumed during this period at the old tariff (tariff until January 1, 2018).

The mathematical form of each tariff cycle is expressed as follows:

$$
\begin{aligned}
& \text { 1. } \quad n_{\text {мin }} \leq n_{i} \leq n_{\mathrm{маx}}, i=\overline{1, m} \\
& \text { 2. } \quad 0 \leq d_{i} n_{i} P, i=\overline{1, m} \\
& \text { 3. } \quad \text { Plan }-\varepsilon_{1} \leq \sum_{i=1}^{m} n_{i} t_{i}<\Pi+\varepsilon_{2} .
\end{aligned}
$$

where: $n_{i}-$ set tariff for the required period;

$\mathrm{m}$ - number of tariff cycles;

$n_{\text {мин }}, n_{\text {мах }}-$ consumption power in minimum and maximum periods, $\mathrm{kW}$;

$t_{i}$ - duration of tariff periods, hours;

$d_{i}=d_{i}\left(n_{i}\right)$ - electricity consumed during the tariff period, $\mathrm{kWh}$;

$\mathrm{P}-\mathrm{a}$ specified amount of electricity (in terms of power supply capacity), $\mathrm{kW}$;

Plan - daily production according to plan.

In this case, the cost per unit of output is expressed as follows:

$$
Z=d_{i}\left(n_{i}\right) b_{i}+\sum_{i=1}^{l} a^{k} \alpha_{k}+C
$$

where: $3_{i}$ - unit costs of manufactured products (for technological processes);

$b_{i}>0$ - Price of $1 \mathrm{kWh}$ of electricity in the specified tariff period, UZS;

$a^{l}, a^{2}, \ldots ., a^{k}-$ consumption of raw materials, fuel, water, etc. (to control the process) consumed per unit of production;

$$
a^{k}=f\left(n_{i}\right), a^{k}>0 ;
$$

$\alpha_{1}, \alpha_{2}, \ldots, \alpha_{l}-$ unit price $a^{k}$

$\mathrm{C}>0$ - fixed costs per unit of production; 
It is advisable to reduce the consumption of production enterprises during the maximum load, which will reduce the cost of the enterprise (DZ) in the implementation of the production plan.

The mathematical expression for this is as follows:

$$
\begin{gathered}
\Delta Z=a \Delta P-Y(\Delta P) ; \\
0 \leq \Delta P \leq \Delta P_{\kappa о р} ;
\end{gathered}
$$

where: $a$ - the cost of $1 \mathrm{kWh}$ of electricity at maximum load of the power system;

$y(\Delta P)$ - additional costs of the enterprise, associated with the regulation of energy consumption of technological devices;

Change of tariff price regimes for periods of "intensive" (maximum) consumption of electricity depends on the annual costs of the enterprise:

$$
Z_{0}=\mathrm{X}_{0}+n_{0} T_{0} \gamma_{0}+P_{0} a+n_{0} T_{0} d_{0}
$$

where: $\mathrm{X}_{0}$ - annual production costs, UZS / year;

$n_{0}$ - period of change of hours in working mode, hours;

$T_{0}$ - planning of annual working hours in the enterprise;

$\gamma_{0}$ - the cost of electricity consumed per unit product before changing the tariff, UZS;

$P_{0}$ - power consumed during the maximum load of the power system before the voltage change, $\mathrm{kW}$;

$a$ - the amount of payment for $1 \mathrm{kWh}$ at the time of maximum load, kWh UZS;

$d_{0}$ - electricity consumption per unit of output before changing the regime, $\mathrm{kWh}$.

If the power consumption $(\Delta \mathrm{P})$ consumed in the maximum periods is reduced by changing the operating mode of the enterprise, the annual consumption capacity $(a \Delta P)$ of the enterprise is also reduced. However, this can lead to a decrease in production. In order to maintain the overall production plan, it will be possible to replace the low-production products in the periods of maximum consumption by producing more products in the night (non-intensive) periods.

$$
n_{0} T_{0}=n_{1}\left(T_{0}-T_{3}\right)+n_{3} T_{3}=n_{0} \alpha_{1}\left(T_{0}-T_{3}\right)+n_{3} \alpha_{3} T_{3}
$$

where: $T_{3}$ - duration of electricity consumption of the enterprise during the "peak" period of the power system;

$\alpha_{1}$ - the coefficient of electrical energy consumed by the power system for the maximum hourly output of the product during the maximum periods;

$\alpha_{3}-$ the coefficient of electrical energy consumed for the product produced per hour minimum during the maximum cycles of the power system.

Changing the operating mode of the enterprise leads to a change in the total annual costs (while maintaining the annual plan). These costs can be expressed as follows:

$$
\begin{aligned}
& \quad Z_{1}=\Delta K(E+p)+\Delta \Phi+\mathrm{X}_{0}+n_{0} \gamma_{0} \times\left[\alpha_{1} \beta_{1}\left(T_{0}-T_{3}\right)+\alpha_{3} \beta_{3} T_{3}\right]+ \\
& +\left(P_{0}-\Delta P\right) a+n_{0} d_{0}\left[\alpha_{1} \beta_{4}\left(T_{0}-T_{3}\right)+\alpha_{3} \beta_{6} T_{3}\right] b
\end{aligned}
$$

where: $\Delta K$ - additional capital values after the change of operating mode;

$\mathrm{E}$ - the ratio of the efficiency of capital investment, taking into account the payments;

$\mathrm{p}$ - depreciation coefficient;

$\Delta \Phi$ - change of working mode;

$\beta_{1}-$ coefficient taking into account the volume of consumption of raw materials and supplies per unit of production at modified working hours; 
$\beta_{3}-$ coefficient taking into account the volume of consumption of raw materials and supplies per unit of production at the time of maximum loads;

$\beta_{4}$-a coefficient that takes into account changes in energy consumption when production changes in the interval $\mathrm{T}_{0}-\mathrm{T}_{3}$;

$\beta_{6}$ - the coefficient that takes into account the change in energy consumption when production changes at time $\mathrm{T}_{3}$;

The annual economic effect of reducing the load on the power system at maximum times is determined by the following expression:

$$
\begin{gathered}
\Delta Z=a \Delta P+n_{0} \gamma_{0}\left[T_{0}\left(1-\alpha_{1} \beta_{1}\right)+T_{3}\left(\alpha_{1} \beta_{1}-\alpha_{3} \beta_{3}\right)\right]+n_{0} d_{0}\left[T_{0}\left(1-\alpha_{1} \beta_{4}\right)+\right. \\
\left.+T_{3}\left(\alpha_{1} \beta_{4}-\alpha_{3} \beta_{6}\right)\right] b-\Delta K(E+p)-\Delta \Phi
\end{gathered}
$$

If $\Delta \mathrm{Z}>0$, it is advisable to reduce the amount of electricity consumption during the maximum load of the enterprise power system.

After a series of transformations, the expediency of the power system for the enterprise during the maximum load cycles is expressed as follows:

$$
\begin{aligned}
& a>\frac{\Delta K(E+p)+\Delta \Phi}{\Delta \mathrm{P}}+\frac{n_{0} \gamma_{0}}{\Delta P}\left[T_{0}\left(\alpha_{1} \beta_{1}-1\right)+T_{3}\left(\alpha_{3} \beta_{3}-\alpha_{1} \beta_{1}\right)\right]+\frac{n_{0} d_{0}}{\Delta P}\left[T_{0}\left(\alpha_{3} \beta_{4}-1\right)+\right. \\
& \left.+T_{3}\left(\alpha_{3} \beta_{6}-\alpha_{1} \beta_{4}\right)\right] b \text {; }
\end{aligned}
$$

Decrease in energy consumption during the night or semi-intense periods $\left(T_{0}-T_{3}\right)$ changes electricity consumption:

$$
\Delta E_{1,2}=n_{0} d_{0}\left(T_{0}-T_{3}\right)\left(1-\alpha_{1} \beta_{4}\right)
$$

During the period of maximum consumption $\left(\mathrm{T}_{3}\right)$ of the power system

$$
\Delta E=n_{0} d_{0} \mathrm{~T}_{3}\left(1-\alpha_{3} \beta_{6}\right)
$$

Changes in total electricity consumption

$$
\Delta E_{\Sigma}=n_{0} d_{0}\left[\left(\mathrm{~T}_{0}-T_{3}\right)\left(1-\alpha_{1} \beta_{4}\right)+T_{3}\left(1-\alpha_{3} \beta_{6}\right)\right]
$$

If $\Delta \mathrm{E}>0$ in the expressions (16) - (18), then in the operating mode the load capacity, ie power consumption decreases, if $\Delta \mathrm{E}<0$, the power consumption increases.

The annual costs of the enterprise before the transition to a stratified tariff regime for daily (annual, seasonal) periods are expressed as follows:

$$
Z=\mathrm{X}_{0}+n_{0} \gamma_{0}\left(\mathrm{~T}_{1}+\mathrm{T}_{2}+\mathrm{T}_{3}\right)+n_{0} d_{0}\left(T_{1} b_{1}+T_{2} b_{2}+T_{3} b_{3}\right)
$$

where: $\mathrm{T}_{1}$ - the duration of the night period;

$\mathrm{T}_{2}$ - the duration of the semi-intensive period;

$\mathrm{T}_{3}$ - "Intensive", ie the duration of the maximum load time of the power system;

$b_{1}, b_{2}, b_{3}$ - Prices for $1 \mathrm{kWh}$ of electricity at night, "semi-intensive" and "intensive";

The maximum load period decreases after the change of power consumption cycles (due to the increase in electricity prices in the "intensive" periods):

$$
\begin{aligned}
& Z_{1} \Delta \mathrm{K}(\mathrm{E}+\mathrm{p})+\mathrm{X}_{0}+\Delta \Phi+n_{0} \gamma_{0}\left(\alpha_{1} \beta_{1} \mathrm{~T}_{1}+\alpha_{2} \beta_{2} \mathrm{~T}_{2}+\alpha_{3} \beta_{3} \mathrm{~T}_{3}\right)+ \\
& +n_{0} d_{0}\left(\alpha_{1} \beta_{4} \mathrm{~T}_{1} b_{1}+\alpha_{2} \beta_{5} \mathrm{~T}_{2} b_{2}+\alpha_{3} \beta_{6} \mathrm{~T}_{3} b_{3}\right)
\end{aligned}
$$


where: $\alpha_{1}, \alpha_{2}, \alpha_{3}$ are the coefficients that take into account the production in the hourly loading cycles $\mathrm{T}_{1}, \mathrm{~T}_{2}$ and $\mathrm{T}_{3}$;

$\beta_{1}, \beta_{2}, \beta_{3}$ - coefficient taking into account changes in consumption of raw materials in production during hourly loading cycles $\mathrm{T}_{1}, \mathrm{~T}_{2}$ and $\mathrm{T}_{3}$;

$\beta_{4}, \beta_{5}, \beta_{6}$-the coefficients that take into account the change in the specific energy consumption when changing during the hourly loading cycles $\mathrm{T}_{1}, \mathrm{~T}_{2}$ and $\mathrm{T}_{3}$.

Annual economic efficiency is achieved by converting $1 \mathrm{kWh}$ of consumption $\left(\mathrm{T}_{3}, \mathrm{~T}_{2}\right)$ during loading time to less valuable time $\left(\mathrm{T}_{1}, \mathrm{~T}_{2}\right)$ :

$$
\begin{gathered}
\Delta Z=n_{0} d_{0}\left[T_{1} b_{1}\left(1-\alpha_{1} \beta_{4}\right)+T_{2} b_{2}\left(1-\alpha_{2} \beta_{5}\right)+T_{3} b_{3}\left(1-\alpha_{3} \beta_{3}\right)\right]+ \\
+n_{0} \gamma_{0}\left[T_{1}\left(1-\alpha_{1} \beta_{1}\right)+T_{2}\left(1-\alpha_{2} \beta_{1}\right)+T_{2}\left(1-\alpha_{2} \beta_{2}\right)+T_{3}\left(1-\alpha_{3} \beta_{3}\right)\right]- \\
-\Delta \mathrm{K}(\mathrm{E}+\mathrm{p})-\Delta \Phi
\end{gathered}
$$

In this case, the power consumption during the night, "semi-intensive" and "intensive" periods $\left(T_{1}, T_{2}, T_{3}\right)$ changes to the following value:

$$
\begin{aligned}
& \Delta E_{1}=n_{0} d_{0} T_{1}\left(1-\alpha_{1} \beta_{4}\right) ; \\
& \Delta E_{2}=n_{0} d_{0} T_{2}\left(1-\alpha_{2} \beta_{5}\right) ; \\
& \Delta E_{3}=n_{0} d_{0} T_{3}\left(1-\alpha_{3} \beta_{6}\right) ;
\end{aligned}
$$

The total change in electrical energy is expressed as follows:

$$
\Delta E_{\Sigma}=n_{0} d_{0}\left[T_{1}\left(1-\alpha_{1} \beta_{4}\right)+T_{2}\left(1-\alpha_{2} \beta_{5}\right)+T_{3}\left(1-\alpha_{3} \beta_{6}\right)\right]
$$

The daily electricity consumption regimes of manufacturing enterprises are consumed according to the cycles of the day using consumption charts. Daily load graphs allow the analysis of the enterprise's electrical equipment in the regulation of the operating mode and for subsequent periods. It will also help to develop measures to determine the regimes of electricity consumption in the near future.

\section{Results and Discussions}

Time-varying tariffs are calculated on the basis of the maximum and minimum hours of electricity consumption per day of the load schedule and are used to determine capacity on this basis. The schedule of electrical loads of manufacturing enterprises is characterized by a certain change in electricity consumption during the day (Figure 1).

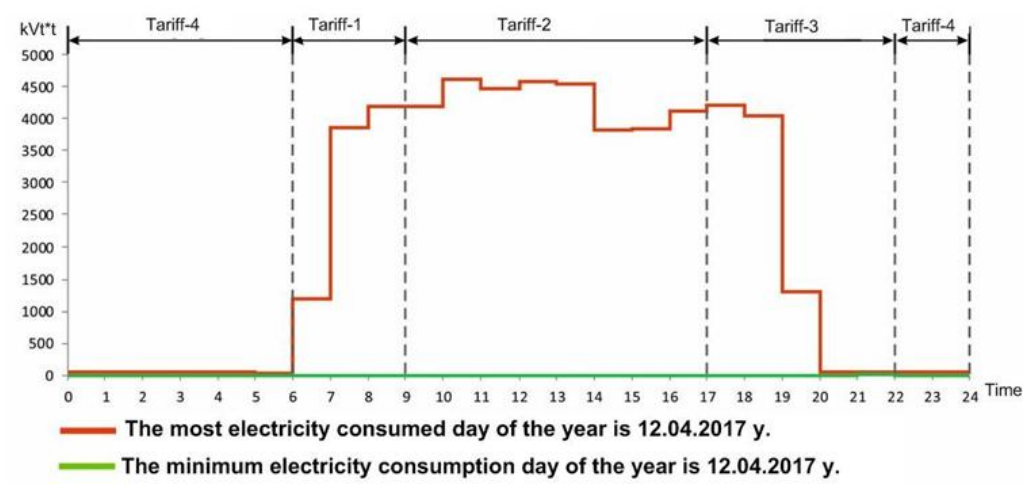

Fig.1. Graph of the maximum and minimum electricity consumption per day of the year at Wangda Metal LLC 
The most complete loading period of power-consuming equipment in enterprises helps to keep accurate calculations, to keep the level of energy consumption at a normal level, and to improve the rhythm of production. For the power system, the regulation of electricity consumption in industrial enterprises is one of the most important tasks [13]: first of all, the rational use of fuel in the production of electricity, as well as increase the reliability of equipment at power plants.

\section{The day of the year that consumes maximum electricity:}

In the process of determining the electricity consumption of "Wangda Metal" LLC, the electricity consumption for the period from June 2017 to June 2018 was analyzed. The maximum daily electricity consumption at the enterprise (April 22, $58369.6 \mathrm{kWh}$ ) and minimum (January $1,78.6 \mathrm{kWh}$ ) is the day of electricity consumption are calculated.

The maximum daily electricity consumption in "Wangda Metal" LLC (April 22, 2018) is $58,369.6 \mathrm{kWh}$. When calculating the maximum daily electricity consumption of the enterprise at the amount of $58369.6 \mathrm{kWh}$ ordinary normal tariff (228.60 UZS as of November 16, 2018), the following result is obtained:

$\mathrm{N}=\mathrm{W} \cdot \alpha=58369,6 \cdot 228,60=\mathbf{1 3} 343290 \mathrm{UZS}$.

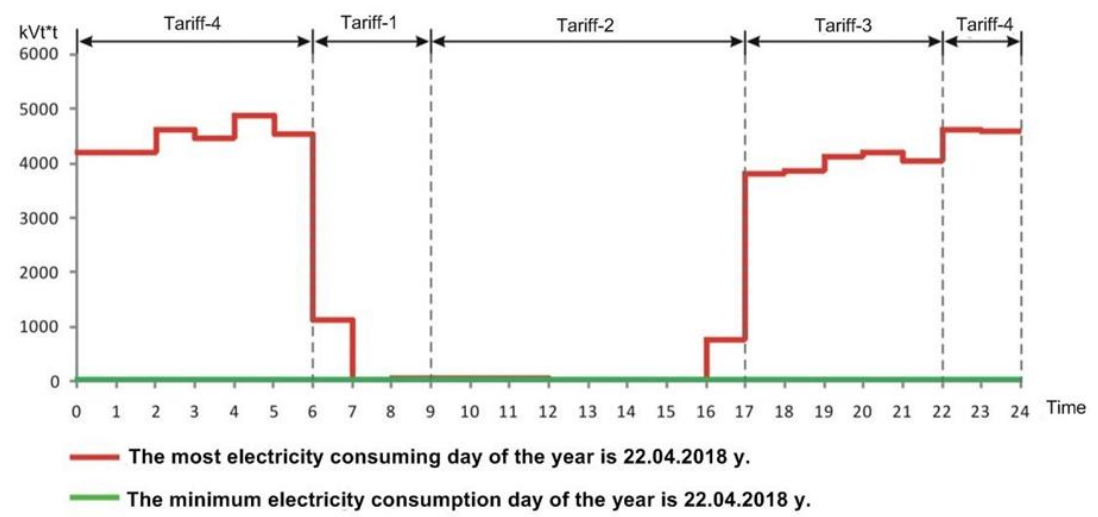

Fig.2. Graph of the maximum and minimum electricity consumption per day of the year at Wangda Metal LLC

Due to night consumption on the day of maximum electricity consumption of the year 13343290 - $13024736,3=\mathbf{3 1 8} 553$ UZS is saved.

The monthly electricity consumption of the enterprise is considered based on the daily electricity consumption.

Table 1. Calculations on time-differentiated tariff amount for the maximum electricity consumption day of the year

\begin{tabular}{|c|c|c|c|c|}
\hline Tariff times & $\begin{array}{c}\text { Daily electricity } \\
\text { consumption, } \\
\mathrm{kWh}\end{array}$ & $\begin{array}{c}\text { The ratio of } \\
\text { periods to total } \\
\text { consumption, } \% .\end{array}$ & $\begin{array}{c}\text { Tariff } \\
\text { price, } \\
\text { UZS } / \mathrm{kWh}\end{array}$ & $\begin{array}{c}\text { Expenditures, } \\
\text { UZS }\end{array}$ \\
\hline From 06:00 to $09: 00$ & 1234,5 & 2 & 342,9 & 423310 \\
\hline From 09:00 to $17: 00$ & 1064,1 & 2 & 228,60 & 243253,2 \\
\hline From 17:00 to $22: 00$ & 20015,5 & 34 & 342,9 & 6863314,9 \\
\hline From 22:00 to $06: 00$ & 36055,5 & 62 & 152,4 & 5494858,2 \\
\hline Total: & $\mathbf{5 8 3 6 9 , 6}$ & $\mathbf{1 0 0}$ & & $\mathbf{1 3 ~ 0 2 4 ~ 7 3 6 , 3}$ \\
\hline
\end{tabular}

The company pays special attention to reducing electricity costs as a result of low electricity consumption during the peak hours in the morning and evening, shifting the main consumption to night periods (Figure 2). 
The maximum daily electricity consumption in "Wangda Metal" LLC (April 22, 2018) is $58,369.6 \mathrm{kWh}$. When calculating this consumption according to the tariff system established until November 16, 2018, the analysis of the daily electricity consumption of the enterprise on 22.04.2018 amounted to the following costs (Table 1).

\section{Annual electricity consumption of "Wangda Metal" LLC:}

In the process of determining the electricity consumption of "Wangda Metal" LLC, the electricity consumption for the period from June 2017 to June 2018 was analyzed.

The annual electricity consumption of the enterprise for this period is $10,401,011.48 \mathrm{kWh}$.

When calculating the annual electricity consumption in "Wangda Metal" LLC at the rate of $10,401,011.48 \mathrm{kWh}$ of ordinary tariff $(228.60 \mathrm{UZS}$ as of November 16, 2018), the following results are obtained:

$\mathrm{N}=\mathrm{W} \cdot \alpha=10401011,48 \cdot 228,60=\mathbf{2} 377 \mathbf{6 7 1}$ 224,32 UZS.

Using the system of differentiated tariffs in this enterprise, the main consumption was at night, ie the volume of electricity consumed by the enterprise at night was the main part of consumption (Table 2).

Table 2. Calculations of annual electricity consumption by time stratified tariff amounts

\begin{tabular}{|l|l|l|l|l|}
\hline \multicolumn{1}{|c|}{ Tariff times } & $\begin{array}{c}\text { Daily electricity } \\
\text { consumption, } \\
\mathrm{kWh}\end{array}$ & $\begin{array}{c}\text { The ratio of } \\
\text { periods to total } \\
\text { consumption, \%. }\end{array}$ & $\begin{array}{c}\text { Tariff } \\
\text { price, } \\
\text { UZS / kWh }\end{array}$ & \multicolumn{1}{|c|}{$\begin{array}{c}\text { Expenditures, } \\
\text { UZS }\end{array}$} \\
\hline From 06:00 to 09:00 & 298627,671 & 3 & 342,9 & 102399428,3859 \\
\hline From 09:00 to 17:00 & 193043,21 & 2 & 228,60 & 44129677,806 \\
\hline From 17:00 to 22:00 & 3076913,625 & 29 & 342,9 & 1055073682,0125 \\
\hline From 22:00 to 06:00 & 6832426,976 & 66 & 152,4 & 1041261871,1424 \\
\hline Total: & $\mathbf{1 0 4 0 1 \mathbf { 0 1 1 , 4 8 }}$ & $\mathbf{1 0 0}$ & & $\mathbf{2 2 4 2 \mathbf { 8 6 4 } 6 5 9 , 3 4 6 8}$ \\
\hline
\end{tabular}

It can be seen from Table 2 that the bulk of the electricity consumed by the enterprise annually falls on the night-time discount period, which is $66 \%$ (Figure 3 ).

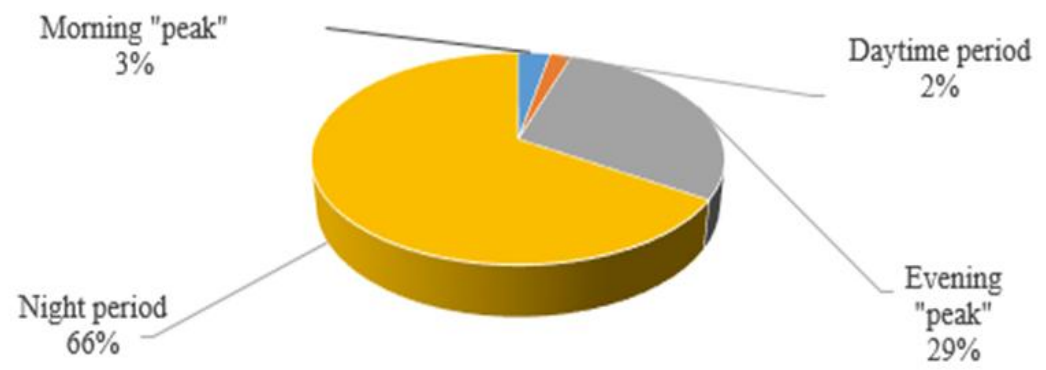

Fig.3. Electricity consumption of "Wangda Metal" for the period from June 2017 to June 2018 view in $\% \mathrm{~s}$

When the enterprise deducts the costs of time-stratified tariffs from the annual ordinary tariff costs due to the correct organization of electricity consumption during the night stimulated a period of the time-stratified tariff system:

2377671 224,32 - 2242864 659,3468=134 806 564,98 UZS.

Mainly, metal fittings are produced in the company. The fact that the cost of these metal fittings is lower than the cost of other metal fittings can be seen from the prices at the Republican Commodity Exchange. This is due to the fact that the company consumes electricity at night, that is, at the expense of full use of the time-stratified tariff system. 


\section{Conclusions}

Summarizing the research results, we can draw the following conclusions:

- The annual electricity consumption of the metal recycling factory during the night periods of the time-stratified tariff system was $66 \%$, which contributes to the reduction of morning and evening "intensive" periods of the power system.

- The system of time-stratified tariffs pays less for electricity consumption at night than in the ordinary tariffs, which leads to lower production costs in "Wangda Metal" LLC. $134,806,564$ UZS were saved from the annual electricity consumption due to the correct use of the time-stratified tariff system at the metal recycling factory.

\section{References}

1. V.V. Mixaylov, Tariff and mode of electricity consumption, Energy, Moscow (1974)

2. I.M. Markovich, Power system modes, Energy, Moscow (1969)

3. T.X. Nasirov, R.A. Sitdikov, V.B. Udovichenko From the experience of developing an expert system for controlling the modes of electric power systems, Topical Issues in Technical and Fundamental Sciences 2, 126-131 (2001)

4. A.V. Ivaneychik, Mode control of technological equipment with piecewise continuous consumption characteristics of power consumption, Scientific Technologies 9, 53-58 (2008)

5. A. Anarbaev, O. Tursunov, R. Zakhidov, D. Kodirov, A. Rakhmatov, N. Toshpulatov, S. Namozov, E. Sabirov, Calculation the dynamic stability zone of the distribution grid with generating sources based on renewable energy, IOP Conf. Ser.: Earth Environ. Sci. 614, 012004 (2020)

6. A. A. Tukenov, Electricity market: from monopoly to competition, Journal of Energy Market 9,10-12 (2005)

7. V. Ye. Sapelik, Regulation of natural monopolies in the wholesale electricity market, Society and Economy (1996)

8. I. A. Soloveva, Forecasting electricity consumption taking into account the factors of the technological and market environment, Scientific Dialogue 7, 19 (2013)

9. N. Toshpulatov, O. Tursunov, D. Kodirov, A. Maksumkhanova, Z. Yusupov, Study on issues of uninterrupted power supply, energy-saving and improving the quality of electrical energy of water facilities, IOP Conf. Ser.: Earth Environ. Sci. 614, 012025 (2020)

10. N. I. Suslov, Factors of Energy Intensity of Production and Energy Saving Efficiency: Experience of Cross-Country Analysis, Economics 1, 22-32 (2007)

11. Kh. Muratov, K. Kadirov, D.Kodirov, Mechanisms of electrical energy management on different tariffs of industrial enterprises, IOP Conf. Ser.: Mater. Sci. Eng. 883, 012163 (2020)

12. Kh. Muratov, K. Sh. Kadirov, A. P. Kushev, Changes in tariff prices for electricity consumption and its impact on the energy system, E3S Web of Conferences 216, 01176 (2020)

13. A Turaev, K. Muratov, O. Tursunov, Comprehensive analysis of the change of pop solar power station output parameters in relation to ambient temperature IOP Conference Series: Earth and Environmental Science, IOP Conf. Ser.: Earth Environ. Sci. 614012003 (2020) 